\title{
Effects of Commission Errors during Noncontingent Reinforcement
}

\author{
Stephanie Hope Jones \\ West Virginia University, shj0001@mix.wvu.edu
}

Follow this and additional works at: https://researchrepository.wvu.edu/etd

Part of the Applied Behavior Analysis Commons

\section{Recommended Citation}

Jones, Stephanie Hope, "Effects of Commission Errors during Noncontingent Reinforcement" (2020). Graduate Theses, Dissertations, and Problem Reports. 7637.

https://researchrepository.wvu.edu/etd/7637

This Thesis is protected by copyright and/or related rights. It has been brought to you by the The Research Repository @ WVU with permission from the rights-holder(s). You are free to use this Thesis in any way that is permitted by the copyright and related rights legislation that applies to your use. For other uses you must obtain permission from the rights-holder(s) directly, unless additional rights are indicated by a Creative Commons license in the record and/ or on the work itself. This Thesis has been accepted for inclusion in WVU Graduate Theses, Dissertations, and Problem Reports collection by an authorized administrator of The Research Repository @ WVU. For more information, please contact researchrepository@mail.wvu.edu. 
Effects of Commission Errors during Noncontingent Reinforcement

Stephanie Hope Jones

Thesis submitted to the Eberly College of Arts and Sciences at West Virginia University in partial fulfilment of the requirements for the degree of Masters of Science in Psychology

\author{
Claire St. Peter, Ph.D., Chair \\ Kathryn Kestner, Ph.D. \\ Barry Edelstein, Ph.D.
}

Department of Psychology
Morgantown, West Virginia
2020
Keywords: Extinction; Fixed-Time Schedules; Noncontingent Reinforcement; Treatment Integrity

Copyright 2020 Stephanie Jones 


\section{ABSTRACT \\ Effects of Commission Errors during Noncontingent Reinforcement}

\section{Stephanie Hope Jones}

Noncontingent reinforcement (NCR) is a behavioral treatment in which a reinforcer is provided at set intervals independently of responding. Although NCR is commonly used, effects of inconsistent implementation (i.e., implementation with integrity failures) during NCR were previously unknown. The current study included six participants, but full-integrity NCR suppressed problem behavior for only three participants. Thus, we evaluated effects of one kind of integrity failure, reinforcement of problem behavior, on NCR outcomes for three children who engaged in inappropriate vocalizations maintained by access to tangible items. Effects of commission errors were idiosyncratic across participants. 


\section{Table of Contents}

Introduction..................................................................................1

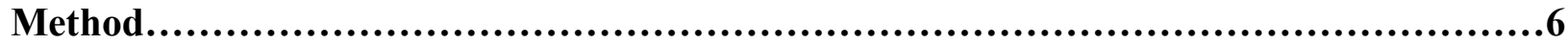

Participants and Setting..........................................................6

Pre-experimental Procedures................................................................7

Data Collection and Interobserver Agreement.....................................8

Experimental Procedures..........................................................10

Results...............................................................................15

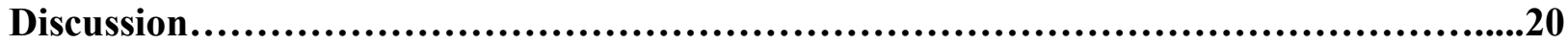

References............................................................................28

Tables \& Figures..............................................................................33 


\section{Effects of Commission Errors during Noncontingent Reinforcement}

Noncontingent reinforcement (NCR) normally consists of providing reinforcers on a time-based schedule independent of responding and withholding reinforcers following problem behavior (extinction; e.g., Phillips et al., 2017; Vollmer et al., 1993). Typical NCR treatments begin with continuous access to the reinforcer. This arrangement produces immediate and dramatic reductions in problem behavior, but continuous access is often not practical over time. Thus, continuous NCR schedules are generally made intermittent once behavior is reduced (Carr et al., 2000). Intermittent NCR consists of periodic delivery of the reinforcer independently of responding after a fixed or variable period (according to fixed-time [FT] or variable-time [VT] schedules). When consistently implemented, intermittent response-independent reinforcer delivery suppresses problem behavior, which has led to the frequent adoption of NCR in behavior-analytic practice (Carr et al., 2009).

Noncontingent reinforcement may have effects through two behavioral mechanisms: satiation and extinction. Each of these mechanisms may be important for the success of NCR treatments over time (Kahng et al., 2000). Satiation reduces the motivation to engage in the response and thus reduces the likelihood of problem behavior maintained by that reinforcer (Vollmer et al., 1993). The initial continuous access to the reinforcer common in clinical applications of NCR may lead to satiation. Extinction refers to breaking the response-reinforcer dependency, such that the response is no longer reinforced. In NCR, the response-reinforcer dependency is broken by delivering the reinforcer independently of responding and by no longer providing the reinforcer contingent on problem behavior. Early research on NCR, which was conducted with nonhumans in laboratory investigations (e.g., Rescorla \& Skucy, 1969), typically involved breaking the response-reinforcer dependency while maintaining similar overall reinforcement rates. The subsequent reduction in response rates was attributed to extinction. 
Extinction may be an active mechanism when intermittent, rather than continuous, reinforcement schedules are used during NCR.

Although intermittent NCR schedules are effective at suppressing problem behavior, initial shifts from continuous access to intermittent schedules commonly result in increased rates of problem behavior (Fritz et al., 2017; Ringdahl et al., 2001; Vollmer et al., 1997). This increase is often temporary, but responding may persist if problem behavior is inadvertently followed in close temporal proximity by a reinforcer (i.e., response-reinforcer contiguity). Such contiguity may occur incidentally when the time-based NCR schedule elapses contiguously with an instance of problem behavior (Ringdahl et al., 2001; Vollmer et al., 1997). This inadvertent contiguity between responses and response-independent reinforcers has been negatively correlated with treatment effects during NCR. For example, Vollmer et al. (1997) successfully suppressed problem behavior with continuous NCR schedules, but responding increased and persisted when NCR was shifted to an intermittent schedule. Upon further analysis, researchers discovered that problem behavior was commonly followed within $10 \mathrm{~s}$ by response-independent reinforcer delivery (Vollmer et al., 1997). Increased response rates coupled with frequent contiguity between responses and reinforcers suggests possible adventitious reinforcement. The researchers altered the schedule to ensure that reinforcers were not delivered unless there was a 10-s window without an instance of problem behavior prior to reinforcer delivery (i.e., a differential reinforcement of other behavior [DRO] schedule). Problem behavior was suppressed following this change.

Response-reinforcer contiguity necessarily occurs when NCR is conducted without programming extinction for problem behavior, as is the case when behavior produces its own maintaining consequences (e.g., self-stimulatory behavior) or when the reinforcer must be 
delivered dependent on the response to ensure safety (e.g., when a caregiver must intervene following attention-maintained aggression or self-injury to prevent physical harm). In most evaluations of NCR without extinction, each instance of problem behavior was reinforced during baseline (according to fixed-ratio [FR] 1 schedules). During treatment, each instance of problem behavior continued to produce reinforcers and reinforcers were delivered on FT schedules. Fritz et al. (2017) eliminated problem behavior for three of five participants during intermittent NCR without extinction. For the other two participants, problem behavior was suppressed during NCR with continuous access, but immediately increased and remained at baseline rates when intermittent NCR schedules were introduced. Similarly, Fisher et al. (1999) found that relatively lean NCR schedules without extinction did not suppress problem behavior; dense NCR schedules without extinction better suppressed behavior, but often still resulted in multiple instances of destructive behavior per minute. The aforementioned evaluations suggest that lean NCR schedules that are implemented concurrently with dense ratio schedules for problem behavior are likely to result in weak treatment effects.

Even when extinction is a programmed treatment component, contiguity may occur when a therapist erroneously reinforces problem behavior. Deviations or inconsistencies from treatment plans are sometimes called treatment-integrity errors. Unplanned delivery of a reinforcer following problem behavior, commonly termed a commission error, has had negative effects across a variety of behavioral interventions (Brand et al., 2019; DiGennaro Reed et al., 2011; Fryling et al., 2012; St. Peter Pipkin et al., 2010). For example, St. Peter Pipkin et al. (2010) found that delivery of reinforcers following problem behavior during differential reinforcement of alternative behavior (DRA) increased rates of problem behavior, even when the 
alternative response still resulted in reinforcers. Intermittent, response-dependent delivery of reinforcers during NCR also could be conceptualized as commission errors.

Although commission errors are likely during NCR, few studies have compared the efficacy of NCR with and without intermittent response-dependent reinforcers (Fryling et al., 2012). Two notable exceptions are Saini et al. (2017) and Borrero et al. (2011). In the study by Saini et al., children with autism engaged in arbitrary responses (button pressing or token dropping) to gain brief access to highly preferred activities. During baseline, the first response after an average of $30 \mathrm{~s}$ elapsed was reinforced (according to a variable-interval [VI] 30-s schedule). The experimenters then conducted NCR with and without extinction. During NCR with extinction, participants received brief access to the activities after $30 \mathrm{~s}$ on average, as long as responding had not occurred in the previous $4 \mathrm{~s}$ (a tandem VT DRO schedule). The target response did not result in reinforcer delivery. During NCR with response-dependent reinforcers, participants received reinforcers independently of responding according to the tandem VT DRO or after a response according to a VI 30-s schedule. Effects of response-dependent reinforcers (i.e., adding the VI 30 to NCR) differed across participants, producing higher response rates, equivalent response rates, or lower response rates relative to NCR with extinction across each of the three participants.

Borrero et al. (2011) also found inconsistent effects of NCR with intermittent responsedependent reinforcers. In this study, three adults with schizophrenia punched holes in paper to earn tokens exchangeable for nickels. During baseline, the first response after $60 \mathrm{~s}$ elapsed was reinforced (a fixed-interval [FI] 60-s schedule). The experimenters then compared NCR with extinction to NCR with response-dependent reinforcers. During NCR with extinction, participants received a token every $60 \mathrm{~s}$ independently of hole punching (according to a FT 60-s 
schedule). During NCR with response-dependent reinforcers, reinforcers were delivered response-independently on an FT 60-s schedule and response-dependently on an FI 60-s schedule. For one participant, responding maintained at baseline rates during NCR with and without response-dependent reinforcers. For another participant, response rates were reduced but not eliminated during NCR with extinction and maintained at baseline rates during NCR with response-dependent reinforcers. For a third participant, responding was suppressed during NCR with and without extinction (Borrero et al., 2011). Thus, NCR was not uniformly effective, even when extinction was used. For the two participants for whom NCR with extinction suppressed behavior, introducing response-dependent reinforcers was detrimental for only one of the participants.

Saini et al. (2017) and Borrero et al. (2011) used NCR to reduce arbitrary responses and delivery of response-dependent reinforcers depended partly on the passage of time (i.e., occurred according to interval schedules). When using NCR to treat problem behavior, the long histories of reinforcement for problem behavior may increase sensitivity to negative effects of commission errors relative to arbitrary responses with short reinforcement histories. Additionally, naturally occurring commission errors may be more likely to occur following a burst of problem behavior (i.e., a ratio schedule) than the passage of time (i.e., an interval schedule). Effects of intermittent ratio schedules concurrent with NCR have not yet been evaluated. Therefore, the purpose of the current study was to systematically vary the likelihood of ratio-based response-dependent reinforcers during NCR as a treatment for problem behavior. Additionally, we evaluated the extent to which the probability of response-contiguous reinforcers predicted treatment outcomes across conditions. 


\section{Method}

\section{Participants and Setting}

Six typically developing males (Charlie, Dante, Arik, Jack, Herbert, and Benji) between the ages of 4 and 6 were enrolled in this study, but only Jack, Herbert and Benji experienced reduced-integrity conditions. According to teacher report, each participant engaged in vocalizations that disrupted the classroom environment daily. All students spoke English and could follow multi-step instructions. Before data collection ensued, the experimenter explained study procedures and received consent from parents. Assent was not obtained due to the participants' ages.

Charlie was a 6-year old male enrolled in the first grade who frequently protested, which was defined as saying no, telling the therapist what to do, bargaining, or complaining. Charlie did not complete the study because he transferred schools during the initial treatment evaluation. Dante was a 5-year old male enrolled in kindergarten whose protesting was defined identically to Charlie's. Dante did not complete the study because he stopped protesting in ways his teachers found problematic following a medication change. Arik was a 5-year old male enrolled in preschool whose protesting was defined as refusing, complaining, and grumbling (clearly audible nonword vocalizations). Like Charlie, Arik did not complete the study because he transferred schools during the initial treatment evaluation. Jack was a 5-year old male enrolled in kindergarten. Jack engaged in nonword vocalizations, including grunting, whining, and screaming. Herbert was a 4-year old male enrolled in preschool whose screaming was defined as nonword vocalizations above conversational volume. Benji was a 6-year old male enrolled in first grade who frequently said "no." 
All participants attended an alternative-education school for children with severe problem behavior when they participated in the study. However, Jack's pre-experimental procedures were conducted in a vacant classroom in his school of origin before he transferred to the alternativeeducation center. The experimenter conducted other sessions in one of three small padded areas (40” by 65") within classrooms (Dante, Charlie, Arik, Jack, Herbert, and Benji) or in a vacant testing room (Jack) in the alternative-education center. For most participants, only the participant, experimenter, and data collectors were present during sessions. For Benji, sessions were conducted in the small padded area within his typical classroom; peers were within earshot but out of view. Sessions were 5 min for Arik, Jack, Herbert, and Benji and 10 min for Dante and Charlie. No more than 12 sessions occurred per day, up to five days per week. Participants were given brief, free access to the activities used as reinforcers between sessions that occurred in the same day.

\section{Pre-experimental Procedures}

Before the experiment proper, the experimenter conducted an open-ended interview with the participants' teachers about idiosyncratic variables in the environment, preferred toys, the most frequent forms of problem behavior, and when the behavior was most likely to occur. The interview was used to inform brief multiple-stimulus-without-replacement (MSWO) preference assessments (Carr et al., 2000) and functional analyses (Iwata et al., 1982/1994).

The MSWOs included five teacher-nominated stimuli. First, the participant was given access to each item for 30-s. Then, the five items were placed equidistant from the participant, and the experimenter prompted the participant to select a toy. The participant was allowed to play with the selected item for $30 \mathrm{~s}$. After the access period, the selected toy was removed from the array, and the participant was asked to select another item until all items had been selected. Because 
Herbert was reported to engage in severe problem behavior following item removal (a necessary component of an MSWO), he chose up to six toys from a large bin of toys before each functional analysis and experimental session in lieu of an initial MSWO.

\section{Data Collection and Interobserver Agreement}

Data were collected during sessions or from video, using computers equipped with Behavior Logger ${ }^{\mathrm{TM}}$ software. Observers collected data on vocalizations using a count measure and reinforcer-access periods using a duration measure. Observers recorded instances of behavior by pressing a key on the keyboard when the behavior occurred; the program logged the topography of behavior and a timestamp for each keystroke. Observers recorded the duration of reinforcer-access periods by clicking a key at the beginning of the reinforcer-access period and again at the end of the period. At the end of the session, the program output a summary that included the rate of count-based responses and the percentage of session for duration-based responses.

Interobserver Agreement. The Behavior Logger ${ }^{\mathrm{TM}}$ program calculated interobserver agreement (IOA) scores. The proportional-agreement calculation was completed by segmenting the session into 10-s intervals, dividing the smaller number of responses recorded in the 10-s interval by the larger number for each response, and averaging across the intervals in the session. Similarly, IOA for the duration-based measure was calculated for each interval by dividing the smaller number of seconds by the larger number of seconds, and averaging across the intervals in the session. Intervals in which the observers agreed on the nonoccurrence of behavior were assigned a coefficient of 1.0. Two independent, trained observers collected IOA data for $41 \%$ of sessions on average for each participant in each phase (see Table 1). Before collecting data for the experiment, new observers received training on how to use the software, an explanation of 
operational definitions with examples and nonexamples, and collected data with experienced data collectors until observers obtained IOA coefficients of at least $90 \%$ for three consecutive sessions on the count and duration measures.

Procedural Fidelity. Procedural-fidelity data were collected for functional analysis and experimental sessions. During the functional analysis, observers used checklists during an average of $37 \%$ of sessions (range $=30 \%-50 \%$ ) for each participant. The fidelity checklists were specific to each condition of the functional analysis. Fidelity coefficients were calculated by dividing the number of correct experimenter responses and the number of opportunities to implement a component within each session and multiplying by 100 , yielding percentage correct experimenter responses $(M=94 \%$, range $=86 \%-99 \%)$.

During experimental sessions, procedural-fidelity coefficients were calculated by analyzing the data output from Behavior Logger (see Table 2). Duration of reinforcer-access periods and reinforcer delivery were analyzed throughout all phases of the experiment. Duration of access for each reinforcer-access period was scored as correct if the duration was between $27 \mathrm{~s}$ to $33 \mathrm{~s}(M=$ $89 \%$ range $=0 \%-100 \%$ ). The criterion for correct reinforcer delivery varied across phases.

During baseline phases, reinforcer delivery was correct if the reinforcer access began within $3 \mathrm{~s}$ of the first response after the interval elapsed $(M=94 \%$, range $=33 \%-100 \%)$. During NCR phases, reinforcer delivery was correct if reinforcer access began within $3 \mathrm{~s}$ of the FT schedule value. Additionally, during reduced-integrity phases, reinforcer delivery was correct when access began within $3 \mathrm{~s}$ of a programmed commission error $(M=96 \%$, range $=60 \%-100 \%)$. Data collectors compared the Behavior Logger output and a checklist with randomized experimenter responses to determine if there was a programmed commission error. 


\section{Experimental Procedures}

Functional Analyses. Functional analyses were conducted with a multielement design. Conditions were selected based on information gathered in the teacher interview. Results of teacher interviews for Charlie, Dante, Jack, Benji, and Arik yielded three test conditions (attention, escape, and tangible) and one control condition (play). Results of the teacher interview for Herbert yielded one test (tangible) and one control (play) condition. Arik experienced an escape-to-attention condition in lieu of a traditional escape condition based on reports that protesting during work frequently resulted in soothing attention. Because Benji's sessions were conducted in the classroom, the experimenter instructed the contingencies to facilitate contact with the contingency while preventing emission of loud or otherwise disruptive behavior.

During the play (control) condition, the participant could access preferred toys and childdirected experimenter attention throughout the session. The play condition started with the experimenter saying "Let's play together." The experimenter avoided presenting demands during this condition. There were no programmed consequences for problem behavior during the play condition.

During the attention condition, experimenter attention was withheld until an instance of the problem behavior occurred. Each instance of problem behavior resulted in $30 \mathrm{~s}$ access to conversational attention from the experimenter. The attention condition started with the experimenter saying, "Wait here while I work.” Dante, Charlie, Arik, and Benji had access to moderately preferred toys during the attention conditions. Jack was not provided with an item during the attention condition because his teacher thought that items may compete with adult attention. Herbert did not experience an attention condition. 
During the escape condition, the experimenter presented a demand identified by the teacher as problem for the child (e.g., writing or identifying letters, completing worksheets, or identifying sight words). The experimenter started escape sessions by saying, "Time to work." The experimenter then prompted the response once every $5 \mathrm{~s}$, using a three-step prompt (vocal, model, and physical) for all written tasks (e.g., writing letters) or a two-step prompt (vocal and model) for spoken tasks (e.g., orally reading sight words). Charlie, Dante, and Jack were prompted to complete written tasks; Arik and Benji were prompted to complete spoken tasks. Following each instance of the target response, the experimenter stopped prompting for 30 s. For Arik, the experimenter also provided conversational attention during the 30 -s escape interval. Herbert did not experience an escape condition.

During the tangible condition, the experimenter provided conversational attention throughout the session. Before the onset of the session, the participants accessed the high-preferred item (identified during the MSWO) or the toy(s) selected at the beginning of the session (Herbert only) for $30 \mathrm{~s}$. The session began when the experimenter said, "My turn" and removed the toys. The toys were returned for $30 \mathrm{~s}$ following each instance of problem behavior. For Herbert, the experimenter removed only the toys with which he engaged during the access period prior to that instance of screaming. For example, if Herbert chose two dinosaurs to play with, but only played with one prior to removal, the experimenter removed only the single dinosaur.

Functional analyses were concluded after at least two sessions of each test condition and three sessions of the control condition were completed, and responding was elevated in one or more test conditions relative to the control condition.

Experimental Design. A within-subject reversal design was used to evaluate effects of commission errors during NCR. Probabilistic commission errors (intermittent response- 
dependent reinforcer deliveries) were introduced following an initial ABAB reversal, where A was baseline and B was NCR with 100\% integrity. All phases included at least five sessions, and continued until response rates were predictable, or until 40 sessions were conducted in the phase. Full-integrity NCR and reduced-integrity phases included an additional criterion for phase termination. Full-integrity NCR phases continued until target responses were reduced by at least $80 \%$ of the mean of the most recent baseline phase for three consecutive sessions. Reducedintegrity phases continued until the obtained commission integrity value closely approximated the programmed value.

All sessions included the same materials and prompts from the experimenter as the functional-analysis condition that resulted in the most consistent elevation of problem behavior. If problem behavior was maintained by multiple reinforcers, we ensured that the other reinforcers were either freely available (e.g., we provided attention and withheld demands throughout sessions for Jack and Benji) or were also delivered according to the NCR schedule (e.g., we also provided access to tangibles during escape intervals for Arik).

Baseline. Baseline consisted of response-dependent delivery of the reinforcer according to variable-interval (Charlie and Dante), or fixed-interval (Arik, Jack, Herbert, and Benji) 15-s schedules. Each reinforcer-access period was $30 \mathrm{~s}$ in duration, and the interval timer was paused during reinforcer access. The experimenter withheld attention during interreinforcer intervals for Dante, Charlie, and Herbert, but provided conversational attention throughout the session for Arik, Jack, and Benji to mimic the classroom environment. For Benji only, the experimenter described the contingency before each session by saying, "When I take the iPad, I am going to keep it for about $15 \mathrm{~s}$. After that, if you say 'no' you can have it back." Similarly to during his functional analysis, this additional instruction was included to lessen the likelihood that Benji 
would engage in more severe forms of problem behavior that would disrupt classroom activities outside of the session area.

Because responding was eliminated during baseline for Dante, we made two sequential modifications to his procedure. First we removed access to preferred items, which had previously been available throughout the session. When problem behavior remained suppressed, we began reinforcing each instance of problem behavior (according to an FR-1 schedule).

Full-Integrity NCR. The NCR procedure consisted of response-independent delivery of the reinforcers according to a fixed-time schedule. The value of the initial FT schedule was set such that reinforcers were delivered twice as often as the mean obtained reinforcement rate during baseline. Initial NCR schedules were calculated by subtracting the duration of reinforcer access from total session duration and dividing the difference by the number of reinforcer-access periods for each baseline session. This calculation yielded approximate interreinforcer intervals (IRI) per session. We then averaged the IRIs and divided by two. This final calculation yielded FT values of 9-s for Charlie and Jack, 13-s for Dante and Arik, and 15-s for Herbert and Benji. The experimenter delivered the reinforcer for $30 \mathrm{~s}$ when the FT timer elapsed, regardless of participant behavior. The FT timer was paused during reinforcer access. Target responses resulted in no programmed consequences.

For Charlie and Dante, NCR conditions included no condition-specific discriminative stimuli. NCR conditions for all other participants included a rule and timer. At the start of each NCR phase (for Arik, Herbert, and Jack) or before each NCR session (Benji), the experimenter said "This time when I take the toy, I'm going to show you a timer. When the timer gets to X [the specific participant's schedule value] seconds, you can have it back." For Arik, the experimenter said, “This time when we work, I'm going to show you a timer. When the timer 
gets to 13 , you can have a break with a toy." During interreinforcer intervals, the therapist held the timer where the participants could see it. The same rule and timer were used during reducedintegrity phases.

NCR with Commission Errors. During reduced-integrity phases, the time-based delivery of reinforcers continued as before but the reinforcer was also delivered following some instances of problem behavior, according to a probabilistic schedule. Jack, Herbert, and Benji experienced two phases of reduced integrity. Jack experienced two phases of $20 \%$ integrity. Herbert and Benji experienced $20 \%$ integrity followed by $80 \%$ integrity. During the $20 \%$ integrity phase, response-dependent reinforcers were delivered according to a random-ratio (RR) 1.25 schedule. This means that 8 in every 10 target responses resulted in reinforcer delivery. During the $80 \%$ integrity phase, response-dependent reinforcers were delivered according to a RR 5; 2 in 10 target responses resulted in reinforcer delivery. The experimenter determined which responses would be reinforced by using randomization software that identified the sequence of responses to be ignored or reinforced (similar to St. Peter Pipkin et al., 2010). Randomization occurred in blocks of 10 in an attempt to distribute errors across sessions. The experimenter kept a printout of the sequence on a clipboard out of the participant's view and delivered the reinforcer when specified by the randomized sequence, or when the FT timer elapsed. If the FT timer elapsed immediately after a target response, the reinforcer was delivered even if the probabilistic sequence called for it to be ignored (to prevent unprogrammed omission errors).

Obtained integrity was calculated by dividing the number of target responses that occured during interreinforcer intervals that were followed by a reinforcer within 3 seconds by the total number of target responses that occurred during the interreinforcer interval. Notably, the 
calculation we used for obtained integrity is also a measure of contiguity. We chose to calculate obtained integrity in this manner to approximate integrity from the participants' perspectives.

\section{Results}

Figure 1 shows functional-analysis results. Each functional analysis resulted in a differentiated outcome. Charlie protested at an average rate of $1.67 / \mathrm{min}($ range $=1.3 / \mathrm{min}$ 2.0/min) exclusively in the escape condition of the functional analysis, suggesting that escape from academic tasks was a reinforcer for protesting. Dante protested more in each of the test conditions relative to the control condition, suggesting that access to attention, escape from academic tasks, and access to preferred items were reinforcers for protesting. However, the attention condition resulted in the most consistent and elevated rates of protesting $(M=.78 / \mathrm{min}$, range $=0 / \mathrm{min}-1.5 / \mathrm{min}$ ). Arik protested more during the escape and tangible conditions relative to the control condition, suggesting that escape from academic tasks and access to preferred items were reinforcers for protesting. However, Arik protested more frequently in the escape condition than the tangible condition $(M=1.6 / \mathrm{min}$, range $=0.2 / \mathrm{min}-3.2 / \mathrm{min})$. Jack vocalized more during all test conditions relative to the control condition, suggesting that access to preferred items, escape from academic tasks, and access to attention were reinforcers for vocalizing. However, the tangible condition resulted in the highest and most consistent elevation of vocalizations $(M=2.8 / \mathrm{min}$, range $=2.2 / \mathrm{min}-3.8 / \mathrm{min})$. Herbert screamed more during the tangible test condition relative to the control condition $(M=1.5 / \mathrm{min}$, range $=1.2 / \mathrm{min}-1.8 / \mathrm{min})$, suggesting that access to preferred items was a reinforcer for screaming. Benji said "no" more in all test conditions relative to the control condition, suggesting that access to preferred items, access to attention, and escape from academic tasks were reinforcers for refusing. However, the tangible test condition resulted in the highest average response rate $(M=1.7 / \mathrm{min}$, range $=$ 
1.2/min-2.0/min). Four of six participants' responding was escalated in multiple test conditions.

The NCR intervention was based on the function that resulted in the highest average response rate for all participants. For Arik, the experimenter also included access to a tangible item (iPad) during reinforcer intervals to address multiple functions simultaneously.

Figure 2 shows results for Charlie, Dante, and Arik. Baseline schedules (VI-15 s for Charlie and Dante and FI-15 s for Arik) resulted in predictable and escalated rates of protesting for Charlie and Arik. However, rates of protesting for Dante decreased and were nearly eliminated for four consecutive sessions following a change to his medication reported by his teacher. We introduced an FR-1 schedule, which resulted in higher rates of responding $(M=$ $.81 / \mathrm{min}$, range $=0 / \mathrm{min}-2.1 / \mathrm{min})$.

Full-integrity NCR was ineffective for all three participants whose data are shown on Figure 2. For Charlie and Arik, we modified NCR to improve treatment effects. Intervention effects were not consistently improved even following multiple modifications. Modifications to Charlie's NCR configuration included the addition of an iPad to reinforcer-access period (labeled 'NCR enriched') and a requirement that no responding could occur in the $2 \mathrm{~s}$ before reinforcer delivery (a differential reinforcement of other behavior schedule [DRO], yielding a tandem FT 7s DRO 2-s schedule). Because Arik's protesting was often related to losing the iPad game, the experimenter showed him how to pause the game and reminded him how several sessions later. Charlie and Arik changed schools before we could identify an effective NCR configuration. Dante's responding remained variable during NCR $(M=0.83 / \mathrm{min}$, range $=0 / \mathrm{min}-1.9 / \mathrm{min})$. However, the topography of his protesting became limited to the phrase "Look at me." This phrase was captured in his definition as telling the experimenter what to do. His teachers did not 
consider "Look at me" a form of problem behavior, and his team no longer thought it was appropriate to remove him from his class to participate in the experiment.

Figure 3 shows the results for Jack, Herbert, and Benji. During baseline, Jack vocalized at moderate to high rates, with a mean of $10.8 / \mathrm{min}$ (range $=2 / \mathrm{min}-33.6 / \mathrm{min}$ ). During the third exposure to baseline, rates of vocalizations decreased, which appeared to be due to satiation. Rates increased once the reinforcer was changed to a new iPad. Vocalizations decreased immediately at the onset of all NCR phases. On average, Jack vocalized $.27 / \mathrm{min}$ (range $=0 / \mathrm{min}$ $.59 / \mathrm{min}$ ) during full-integrity NCR, yielding a 97\% reduction of problem behavior relative to baseline.

During the first $20 \%$ integrity phase, Jack vocalized twice when he did not have reinforcer access. Both of these vocalizations resulted in the delivery of the iPad according to the probabilistic schedule. Thus, although the programmed integrity level was $20 \%$, the obtained integrity level was $0 \%$. The abbreviated exposure may not have allowed his behavior to sufficiently contact the contingency. To ensure contact with reduced-integrity contingencies, all subsequent reduced-integrity phases were conducted until the obtained integrity approximated the programmed integrity. Following this modification, the obtained integrity across 40 sessions in the replication of the $20 \%$ phase was $23 \%$. During this replication of NCR $20 \%$, Jack vocalized $.69 / \mathrm{min}$ on average (a 93\% reduction relative to baseline). Thus, NCR was effective for Jack even with frequent commission errors.

Herbert's rates of screaming were $3.17 / \mathrm{min}$ across baseline phases (range $=.19 / \mathrm{min}$ 14.16/min). Similar to results for Jack, NCR resulted in immediate response suppression. Herbert screamed $.51 / \mathrm{min}$ on average $($ range $=.19 / \mathrm{min}-.99 / \mathrm{min})$ during full-integrity NCR, yielding a $93 \%$ reduction in screaming relative to baseline. During the $20 \%$ integrity phase for Herbert, 
obtained integrity was $29 \%$. Response rates were variable during NCR $20 \%$ for Herbert.

Screaming occurred at low rates 13 sessions, then response rates increased above previous baseline rates $(M=2.23 / \mathrm{min}$, range $=0 / \mathrm{min}-12.15 / \mathrm{min})$ Overall, NCR $20 \%$ yielded a $30 \%$ reduction relative to baseline and a $337 \%$ increase relative to full-integrity NCR. This suggests that frequent commission errors were detrimental to NCR for Herbert. During the $80 \%$ integrity phase, response rates were suppressed for seven sessions, and then became more variable for the subsequent 10 sessions. This period of variability included two sessions with rates similar to the $20 \%$ integrity phase. Responding returned to low rates for 17 sessions $(M=1.13 / \mathrm{min}$, range $=$ 0/min- $11.98 / \mathrm{min}$ ). Overall, NCR $80 \%$ yielded a $64 \%$ reduction relative to baseline and a $122 \%$ increase relative to full-integrity NCR. Obtained integrity was $69 \%$. To control for phase length as a possible variable, we conducted an additional full-integrity NCR phase for 19 sessions (more than the number of sessions that occurred before escalation in the $20 \%$ phase). Fullintegrity NCR continued to be efficacious even when the phase length was extended.

Benji engaged in moderate, variable rates of refusals during baseline $(M=1.55 / \mathrm{min}$, range $=$ $.19 / \mathrm{min}-4.19 / \mathrm{min})$. Variability continued during full-integrity NCR with differing degrees of variability across phases. Although rates were near-zero during the first three sessions of Benji's first full-integrity NCR phase, variability increased through the rest of the phase before meeting the suppression criteria after 36 sessions $(M=.54 / \mathrm{min}$, range $=0 / \mathrm{min}-2.8 / \mathrm{min})$. Benji's second exposure to full-integrity NCR resulted in consistent response suppression $(M=.22 / \mathrm{min}$, range $=$ 0/min-.59/min). The replication of full-integrity NCR between the $20 \%$ and $80 \%$ phases resulted in suppression of responding in six sessions $(M=.23 / \mathrm{min}$, range $=0 / \mathrm{min}-1 / \mathrm{min})$. The last fullintegrity NCR phase for Benji resulted in variable rates of responding and the highest rates previously recorded in a full-integrity NCR phase $(M=.59 / \mathrm{min}$, range $=0 / \mathrm{min}-4.16 / \mathrm{min})$. 
Overall, full-integrity NCR yielded a $68 \%$ reduction in refusals relative to baseline $(M=.50 / \mathrm{min}$, range $=0 / \mathrm{min}-4.2 / \mathrm{min})$. Benji's responding was variable during the $20 \%$ phase $(M=.43 / \mathrm{min}$, range $=0 / \mathrm{min}-1.6 / \mathrm{min}$ ), yielding a $72 \%$ decrease in average rate of refusals relative to baseline and a $14 \%$ decrease relative to full-integrity NCR. Obtained integrity during this phase was $26 \%$. The $80 \%$ phase resulted in variable responding similarly to $20 \%$ integrity $(M=.55 / \mathrm{min}$, range $=$ 0/min-2.39/min), yielding a $65 \%$ decrease in average rate of refusals relative to baseline and a $10 \%$ increase in average rate of refusals relative to full-integrity NCR. Obtained integrity for the $80 \%$ phase was $57 \%$. The phase was ended although the obtained integrity did not approximate programmed integrity because 40 sessions were completed. The variability in response rates during full-integrity NCR makes it difficult to make conclusive statements about effects of NCR with response-dependent reinforcers.

Figure 4 shows the proportion of reinforcers that occurred within $3 \mathrm{~s}$ of a response by condition. This was calculated by dividing the number of reinforcer deliveries that occurred within $3 \mathrm{~s}$ of a response in each condition by the total number of reinforcer deliveries in that condition. This calculation yielded a proportion between 0.0 and 1.0 , with a value of 1 indicating that every reinforcer delivery occurred within $3 \mathrm{~s}$ of a response. Values of 1.0 would be expected when all reinforcers are dependent on responding (e.g., interval or ratio schedules). Values of 0.0 would be expected when omission contingencies are arranged (e.g., DRO schedules). Intermediate values may occur during NCR, depending on the extent to which responsereinforcer contiguity occurs. For each participant, the proportion was higher in low-integrity conditions than high-integrity conditions. However, the proportion differed across participants for full-integrity NCR. For participants for whom NCR was ineffective, a larger proportion of reinforcers followed a response than occurred for participants for whom NCR was effective. 
Table 3 lists average problem behavior per min when the reinforcer was restricted and the average proportion of reinforcers delivered within $3 \mathrm{~s}$ of a response across conditions for each participant. Figure 5 depicts these data graphically. Overall, rates of problem behavior increased with concomitant increases in the probability of a reinforcer following a response. Notably, however, there was considerable intersubject variability in the extent to which rates increased; rates remained relatively low for Herbert, Benji, Charlie, and Dante even during baseline, when all reinforcers were delivered response-dependently.

\section{Discussion}

The primary purpose of the current study was to evaluate effects of commission errors during NCR. We could not evaluate effects of commission errors for three participants because full-integrity NCR did not effectively suppress behavior. For the participants for whom NCR was initially effective, commission errors had idiosyncratic effects: treatment effects maintained for Jack and Benji, but were lost at $20 \%$ and $80 \%$ for Herbert.

Effects of commission errors during NCR in our study replicate those of Borrero et al. (2011) despite differences in population (children v. adults), response topographies (clinically significant v. arbitrary), and reinforcers (identified via functional analysis v. money). Recall that the results of Borrero et al. included a participant whose responding was suppressed during NCR with and without commission errors (similar to Jack), a participant whose responding was reduced during NCR and increased to baseline levels during NCR with commission errors (similar to Herbert), and a participant whose responding was elevated in NCR with and without commission errors (similar to Benji). In conjunction, our data and those of Borrero et al. (2011) suggest that NCR with commission errors results in idiosyncratic effects across participants. 
Borrero et al. (2011) suggested that response rate during full-integrity NCR may provide insight into how commission errors will impact NCR. They found that responding was more likely to remain suppressed after commission errors were introduced when responding was eliminated or nearly eliminated during full-integrity NCR. In the current study, Jack's responding was almost completely suppressed during full-integrity NCR (97\% reduction relative to baseline) and NCR with commission errors maintained its efficacy. However, NCR was similarly effective for Herbert (resulting in 93\% suppression relative to baseline), but commission errors were detrimental to treatment outcomes. It is possible that response rates during full-integrity NCR are only partially predictive of response rates during NCR with commission errors.

Another variable that may impact the likelihood that response rates increase during NCR with commission errors is the reinforcement history of the target response. Recall that Borrero et al. analyzed impacts of intermittent response-dependent reinforcers on an arbitrary response with a relatively short reinforcement history. Arbitrary responses are often taught in the context of the experiment and are unlikely to have an extraexperimental history of reinforcement. In contrast, we measured problem behavior with a long and varied reinforcement history. It is possible that our participants came to sessions with varied extraexperimental histories (i.e., some participants may have received reinforcers for problem behavior between experimental sessions) because we selected responses that occurred frequently in the classroom environments (St. Peter Pipkin et al., 2010). Extraexperimental histories would be unlikely to affect arbitrary responding because arbitrary responses are often taught in the context of the experiment. Additionally, in other domains, responses with longer reinforcement histories have been found to be more prone to relapse than responses with shorter reinforcement histories (Bruzek et al., 2009). It is possible 
that responses with longer reinforcement histories are also more prone to relapse following exposure to commission errors (Lattal \& St. Peter Pipkin, 2009).

Other evaluations have indicated that reinforcement history within the experiment also affects responding during treatment (St. Peter Pipkin \& Vollmer, 2009). One relevant aspect of within-experiment reinforcement history is the baseline schedule used prior to treatment (St. Peter Pipkin \& Vollmer, 2009). Most applied evaluations of NCR use FR-1 schedules to maintain responding during baseline. However, we used FI 15-s schedules to facilitate creation of denser NCR schedules during treatment relative to baseline. The use of FI 15-s schedules instead of FR-1 schedules during baseline may have decreased the likelihood that commission errors were detrimental to treatment. FI 15-s schedules result in lower reinforcement rates than FR-1 schedules, making responses with a history of FI 15-s schedules less prone to relapse than responses with a history of FR-1 schedules (Fisher et al., 2019). Additionally, FR-1 schedules may have resulted in different patterns of responding at the transition to NCR relative to FI 15-s schedules (e.g., shorter latencies to respond, higher response rates). High-rate responding at the onset of NCR treatment is more likely to encounter contiguous response-independent reinforcers and be strengthened accordingly than is low-rate responding (Catania \& Keller, 1981). Further research is needed to understand the relation between baseline schedules and subsequent treatment outcomes with and without integrity errors.

An additional limitation of the current evaluation was that participants could access reinforcers for brief, variable periods between sessions. Given that these access periods varied in duration, it is possible that participants were less motivated to access the reinforcer during sessions that were preceded by long pre-session access periods. Because we did not collect data on these durations of access, we are unable to explicitly evaluate potential impacts of variable 
access periods on subsequent behavior. Future research should take precautions to keep access to reinforcers between of experimental sessions constant or directly assess effects of pre-session access to reinforcers on the efficacy of NCR.

The inconsistent efficacy of NCR without commission errors during this study complicates interpretation of results. Full-integrity NCR was ineffective or inconsistently effective for four of the participants (Charlie, Dante, Arik, and Benji). Weak effects of NCR occurred despite inclusion of several procedural details designed to enhance NCR efficacy. For example, we used a timer and rule to signal the NCR schedule for Arik, Jack, Herbert, and Benji. The use of the timer may have increased the efficacy of NCR by signaling the delay to reinforcer delivery (Vollmer et al., 1999) or by signaling an extinction period (Gouboth et al., 2007). We chose to use the same timer during reduced-integrity phases to isolate effects of commission errors; however, future research should evaluate impacts of omitting treatment-specific signals on rates of problem behavior. Additionally, we provided information about the responseindependent delivery of reinforcers before NCR phases (“This time when I take the toy, I'm going to show you a timer. When the timer gets to X [the specific participant's schedule value] seconds, you can have it back"). This statement may have resulted in rule-governed behavior. Collectively, the timer and rule may have facilitated immediate response suppression for some participants (e.g., Jack), disrupting high-rate responding that occurred during baseline and preventing inadvertent contiguity during the transition to NCR (Catania \& Keller, 1981). It is possible that sensitivity to these procedural details (e.g., the extent to which participants attended to the timer or had a history of rule-following) could predict the subsequent efficacy of NCR.

The initial efficacy of NCR may have been affected by the availability of items or activities throughout the session (Fuhrman et al., 2018). For example, Charlie, Dante, and Arik, 
for whom NCR was ineffective, could access items or activities only through the intermittent time-based schedule during NCR. In contrast, attention was continuously available for Jack and Benji, and other toys were continuously available for Herbert. Although the availability of these items did not eliminate responding during baseline, it is possible that the availability of alternative activities enhanced the efficacy of NCR (Fuhrman et al., 2018) or reduced motivation to engage in problem behavior during reduced-integrity sessions. Of particular note is that the items or activities that were freely available had been previously identified as reinforcers during the functional analysis. Future research should evaluate relative efficacy of NCR with and without alternative reinforcers.

An additional modification previous research on NCR has used is to program omission contingencies (e.g., DRO schedules; Saini et al., 2017; Vollmer et al., 1997) to prevent inadvertent response-reinforcer contiguity. Omission contingencies ensure that reinforcers do not occur contiguously with responses and result in suppressed rates of problem behavior (Vollmer et al., 1997). Previous studies have included omission contingencies pre-emptively (e.g., Saini et al., 2017) or after NCR without omission contingencies failed to suppress problem behavior (e.g., Vollmer et al., 1997). We chose not to use omission contingencies pre-emptively to prevent omission errors (i.e., failing to deliver the reinforcer according to the NCR schedule) and to evaluate possible impacts of inadvertent response-reinforcer contiguity. However, we did implement NCR with an omission contingency for Charlie after initial NCR treatments were ineffective. His response rates became more variable but did not meet our suppression criteria before he transferred schools. The increased variability of Charlie's response rates following the addition of the omission contingency highlights one weakness of omission contingencies; they 
increase the risk of negative side-effects of extinction (Vollmer et al., 1993). These side effects (e.g., extinction-bursts, extinction-induced variability) may be intolerable in some environments. Additionally, inclusion of an omission contingency requires monitoring behavior for at least a brief period, which may increase the need for staff time and be problematic for staff that are managing the behavior of many individuals (Vollmer et al., 1993). When staff are managing the behavior of many individuals, omission contingencies may not be possible and responsereinforcer contiguity is likely to be uncontrolled. This may be problematic because responsereinforcer contiguity likely contributes to weak effects of NCR (Vollmer et al., 1997). For example, the proportion of reinforcers that followed a response within $3 \mathrm{~s}$ during full-integrity NCR varied across participants in our study. For participants with generally higher proportions of responses followed by reinforcer delivery, NCR was less effective. This finding aligns with previous research on negative impacts of inadvertent contiguity during NCR (Ringdahl et al., 2001; Vollmer et al., 1997). Of note, we analyzed contiguity using smaller window sizes (3 s) relative to other applied evaluations (e.g., 10 s; Ringdahl et al, 2001; Vollmer et al., 1997). We chose to use smaller window sizes because our NCR schedules were dense (e.g., as short as 9 s). However, these smaller window sizes may have underestimated contiguous response-reinforcer pairings. Future research should evaluate what window size best enhances the predictive validity of contiguity analyses.

Generally, treatment-integrity research suggests that high-integrity implementation results in better treatment outcomes and that integrity errors have idiosyncratic effects across participants, interventions, and error types (Brand et al., 2019). Although effects of different types of treatment-integrity errors are idiosyncratic, Brand et al. (2019) found that commission errors were rarely evaluated in isolation in treatment-integrity studies. Only two studies 
(DiGennaro Reed et al., 2011; Leon et al., 2014) have parametrically evaluated impacts of commission errors in isolation in an applied setting, even though descriptive data suggest that caregivers commonly reinforce problem behavior during extinction (Arkoosh et al., 2007; Fryling et al., 2012). Our choice to analyze effects of commission errors in isolation is a unique contribution to the literature, but it leaves the analysis of treatment-integrity errors during NCR incomplete. Further research on different kinds of treatment-integrity errors (e.g., omission errors, blended errors) during NCR is warranted.

Although we only analyzed one error type, our data still suggest that practitioners should be wary when recommending NCR due to idiosyncratic effects of commission errors, even when integrity scores would otherwise be considered acceptable. For example, integrity scores of $80 \%$ are included in behavior-analytic publications and are used as a mastery criterion during staff training (Fiske, 2008; Hagermoser Sanetti \& Kratochwill, 2008), but NCR conducted with 80\% integrity was detrimental for Herbert. In contrast, St. Peter Pipkin et al. (2010) found that interventions based on differential reinforcement maintained their efficacy when implemented with $80 \%$ integrity. It is possible that the requisite level of treatment integrity to improve outcomes varies from treatment to treatment.

Treatment-integrity errors may be more detrimental during NCR relative to DRA because the only way to increase reinforcement rate during NCR with commission errors is to engage in problem behavior. When DRA is implemented with treatment-integrity errors, engaging in appropriate behavior can increase reinforcement rate. It may be important for participants to have an appropriate way to increase reinforcement rate given that reinforcer value may fluctuate within or across sessions. If commission errors are likely during NCR, or extinction is not a practical intervention component, practitioners may want to consider implementing DRA instead 
of, or in combination with, NCR (e.g., Fritz et al., 2017). It is possible that teaching and reinforcing an alternative response concurrently with NCR treatment would reduce negative impacts of commission errors during NCR. However, given the differences in efficacy during reduced-integrity treatment, practitioners may want to consider implementing DRA instead of NCR if practical and possible. Notably, these comparisons are drawn across, rather than within, participants. Given the idiosyncratic effects of treatment-integrity errors across participants in the current study, future research should evaluate relative impacts of integrity errors during NCR and DRA in a within-subject design.

Overall, our results are consistent with previous treatment-integrity research. First, highintegrity interventions generally resulted in therapeutic outcomes that were more consistent than low-integrity interventions. Second, our study contributes to the existing research suggesting that effects of treatment-integrity errors are idiosyncratic across behavioral interventions. For example, treatment-integrity scores that are considered "high" and yield therapeutic outcomes during DRA negatively impact NCR. These differences across behavioral interventions highlight the need for more research on effects of integrity errors during other common interventions (such as DRO) and identification of treatment modifications that protect against negative impacts of treatment-integrity errors during NCR and other behavioral interventions. 


\section{References}

Arkoosh, M. K., Derby, K. M., Wacker, D. P., Berg, W., McLaughlin, T. F., \& Barretto, A. (2007). A descriptive evaluation of long-term treatment integrity. Behavior Modification, 31(6), 880-895. https://doi.org/10.1177/0145445507302254

Borrero, J. C., Bartels-Meints, J. A., Sy, J. R., \& Francisco, M. T. (2011). Fixed-time schedule effects in combination with response-dependent schedules. Journal of Applied Behavior Analysis, 44(1), 163-167. https://doi.org/10.1901/jaba.2011.44-163

Brand, D., Henley, A. J., DiGennaro Reed, F. D., Gray, E., \& Crabbs, B. (2019). A review of published studies involving parametric manipulations of treatment integrity. Journal of Behavioral Education, 28(1), 1-26. https://doi.org/10.1007/s10864-018-09311-8

Bruzek, J. L., Thompson, R. H., \& Peters, L. C. (2009). Resurgence of infant caregiving responses. Journal of the Experimental Analysis of Behavior, 92(3), 327-343. https://doi.org/10.1901/jeab.2009-92-327

Carr, J. E., Coriaty, S., Wilder, D. A., Gaunt, B. T., Dozier, C. L., Britton, L. N., Avina, C., \& Reed, C. L. (2000). A review of "noncontingent" reinforcement as treatment for the aberrant behavior of individuals with developmental disabilities. Research in Developmental Disabilities, 21(5), 377-391. https://doi.org/10.1016/s08914222(00)00050-0

Carr, J. E., Nicolson, A. C., \& Higbee, T. S. (2000). Evaluation of a brief multiple-stimulus preference assessment in a naturalistic context. Journal of Applied Behavior Analysis, 33(3), 353-357. https://doi.org/10.1901/jaba.2000.33-353

Carr, J. E., Severtson, J. M., \& Lepper, T. L. (2009). Noncontingent reinforcement is an empirically supported treatment for problem behavior exhibited by individuals with 
developmental disabilities. Research in Developmental Disabilities, 30(1), 44-57. https://doi.org/10.1016/j.ridd.2008.03.002

Catania, A. C., \& Keller, K. J. (1981). Contingency, contiguity, correlation, and the concept of causation. In Harzem, P., \& Zeiler, M. D. (Eds.), Predictability, correlation, and contiguity (pp 125-167). John Wiley \& Sons Ltd.

DiGennaro Reed, F. D., Reed, D. D., Baez, C. N. \& Maguire, H. (2011). A parametric analysis of errors of commission during discrete-trial training. Journal of Applied Behavior Analysis, 44(3), 611-615. https://doi.org/10.1901/jaba.2011.44-611

Fisher, W. W., Saini, V., Greer, B. D., Sullian, W. E., Roane, H. S., Fuhrman, A. M., Craig, A. R., \& Kimball, R. T. (2019). Baseline reinforcement rate and resurgence of destructive behavior. Journal of the Experimental Analysis of Behavior, 111(1): 75-93. https://doi.org/10.1002/jeab.488

Fisher, W. W., Thompson, R. H., DeLeon, I. G., Piazza, C. C., Kuhn, D. E., Rodriguez-Catter, V., \& Adelinis, J. D. (1999). Noncontingent reinforcement: Effects of satiation versus choice responding. Research in Developmental Disabilities, 20(6), 411-427. https://doi.org/10.1016/s0891-4222(99)00022-0

Fiske, K. E. (2008). Treatment integrity of school-based behavior analytic interventions: a review of the research. Behavior Analysis in Practice, 1(2), 19-25. https://doi.org/10.1007/BF03391724

Fritz, J. N., Jackson, L. M., Stiefler, N. A., Wimberly, B. S., \& Richardson, A. R. (2017). Noncontingent reinforcement without extinction plus differential reinforcement of alternative behavior during treatment of problem behavior. Journal of Applied Behavior Analysis, 50(3), 590-599. https://doi.org/10.1002/jaba.395 
Fryling, M. J., Wallace, M. D., \& Yassine, J. N. (2012). Impact of treatment integrity on intervention effectiveness. Journal of Applied Behavior Analysis, 45(2), 449-453. https://doi.org/10.1901/jaba.2012.45-449

Fuhrman, A. M., Greer, B. D., Zangrillo, A. N., \& Fisher, W. W. (2018). Evaluating competing activities to enhance functional communication training during reinforcement schedule thinning. Journal of Applied Behavior Analysis, 51(4), 931-942. https://doi.org/10.1002/jaba.486

Gouboth, D., Wilder, D. A., \& Booher, J. (2007). The effects of signaling stimulus presentation during noncontingent reinforcement. Journal of Applied Behavior Analysis, 40(4), 725730. https://doi.org/10.1901/jaba.2007.725-730

Hagermoser Sanetti, L. M., \& Kratochwill, T. R. (2008). Treatment integrity in behavioral consultation: Measurement, promotion, and outcomes. International Journal of Behavioral Consultation and Therapy, 4(1), 95-114.https://doi.org/10.1037/h0100835

Iwata, B. A., Dorsey, M. F., Slifer, K. J., Bauman, K. E., \& Richman, G. S. (1994). Toward a functional analysis of self-injury. Journal of Applied Behavior Analysis, 27(2), 197-209. https://doi.org/10.1901/jaba.1994.27-197

Kahng, S.W., Iwata, B. A., Thompson, R. H., \& Hanley, G. P. (2000). A method for identifying satiation versus extinction effects under noncontingent reinforcement schedules. Journal of Applied Behavior Analysis, 33(4), 419-432. https://doi.org/10.1901/jaba.200.33-419

Lattal, K. A., \& St. Peter Pipkin, C. (2009). Resurgence of previously reinforced responding: Research and application. The Behavior Analyst Today, 10(2), 254-266. http://dx.doi.org/10.1037/h0100669

Leon, Y., Wilder, D. A., Majdalany, L., Myers, K., \& Saini, V. (2014). Errors of omission and commission during alternative reinforcement of compliance: The effects of varying levels 
of treatment integrity. Journal of Behavioral Education, 23(1), 19-33.

https://doi.org/10.1007/s10864-013-9181-5

Phillips, C. L., Iannaccone, J. A., Rooker G. W., \& Hagopian, L. P. (2017). Noncontingent reinforcement for the treatment of severe problem behavior: An analysis of 27 consecutive applications. Journal of Applied Behavior Analysis, 50(2), 357-376. https://doi.org/V10.1002/jaba.376

Rescorla, R. A., \& Skucy, J. C. (1969). Effect of response-independent reinforcers during extinction. Journal of Comparative and Physiological Psychology, 67(3), 381-389. https://doi.org/10.1037/h0026793

Ringdahl, J. E., Vollmer, T. R., Borrero, J. C., \& Connell, J. E. (2001). Fixed-time schedule effects as a function of baseline reinforcement rate. Journal of Applied Behavior Analysis, 34(1), 1-15. https://doi.org/10.1901/jaba.2001.34-1

Saini, V., Fisher, W. W., \& Pisman, M. D. (2017). Persistence during and resurgence following noncontingent reinforcement implemented with and without extinction. Journal of Applied Behavior Analysis, 50(2), 377-392. https://doi.org/10.1002/jaba.380

St. Peter Pipkin, C., \& Vollmer, T. R. (2009). Applied implications of reinforcement history effects. Journal of Applied Behavior Analysis, 42(1), 83-103. https://doi.org/10.1901/jaba.2009.42-83

St. Peter Pipkin, C. Vollmer, T. R., \& Sloman, K. N. (2010). Effects of treatment integrity failures during differential reinforcement of alternative behavior: A translational model. Journal of Applied Behavior Analysis, 43(1), 47-70. https://doi.org/10.1901/jaba.2010.4347 
Vollmer, T. R., Iwata, B. A., Zarcone, J.R., Smith, R. G., \& Mazaleski, J. L. (1993). The role of attention in the treatment of attention-maintained self-injurious behavior: Noncontingent reinforcement and differential reinforcement of other behavior. Journal of Applied Behavior Analysis, 26(1), 9-21. https://doi.org/10.1901/jaba.1993.26-9

Vollmer, T. R., Borrero, J. C., Lalli, J. S., \& Daniel, D. (1999). Evaluating self-control and impulsivity in children with severe behavior disorders. Journal of Applied Behavior Analysis, 32(4), 451-466. https://doi.org/10.1901/jaba.1999.32-451

Vollmer, T. R., Ringdahl, J. E., Roane, H. S., \& Marcus, B. A. (1997). Negative effects of noncontingent reinforcement. Journal of Applied Behavior Analysis, 30(1), 161-164. https://doi.org/10.1901/jaba.1997.30-161 


\section{Table 1}

Interobserver Agreement (IOA) across participants and phases

\begin{tabular}{ccccc}
\hline Participant & Phase & $\begin{array}{c}\text { Sessions } \\
\text { with IOA }\end{array}$ & $\begin{array}{c}\text { Average Agreement } \\
(\text { Range) }\end{array}$ & $\begin{array}{c}\text { Average Agreement } \\
\text { (Range): Reinforcer }\end{array}$ \\
& & & Vocalizations & Access \\
\hline Charlie & Baseline & $25 \%$ & $87 \%(76 \%-97 \%)$ & $95 \%(91 \%-99 \%)$ \\
Charlie & Full-Integrity NCR & $20 \%$ & $98 \%(94 \%-100 \%)$ & $96 \%(94 \%-98 \%)$ \\
Dante & Baseline & $41 \%$ & $99 \%(94 \%-100 \%)$ & $98 \%(96 \%-100 \%)$ \\
Dante & Full-Integrity NCR & $36 \%$ & $96 \%(90 \%-100 \%)$ & $95 \%(93 \%-97 \%)$ \\
Arik & Baseline & $33 \%$ & $85 \%(77 \%-93 \%)$ & $92 \%(86 \%-98 \%)$ \\
Arik & Full-Integrity NCR & $33 \%$ & $76 \%(75 \%-77 \%)$ & $80 \%(77 \%-83 \%)$ \\
Jack & Baseline & $59 \%$ & $88 \%(75 \%-98 \%)$ & $98 \%(94 \%-100 \%)$ \\
Jack & Full-Integrity NCR & $75 \%$ & $95 \%(90 \%-100 \%)$ & $97 \%(94 \%-100 \%)$ \\
Jack & Reduced-Integrity NCR & $47 \%$ & $94 \%(83 \%-100 \%)$ & $97 \%(91 \%-100 \%)$ \\
Herbert & Baseline & $52 \%$ & $92 \%(54 \%-100 \%)$ & $97 \%(77 \%-100 \%)$ \\
Herbert & Full-Integrity NCR & $43 \%$ & $98 \%(85 \%-100 \%)$ & $92 \%(62 \%-100 \%)$ \\
Herbert & Reduced-Integrity NCR & $50 \%$ & $93 \%(59 \%-100 \%)$ & $95 \%(82 \%-100 \%)$ \\
Benji & Baseline & $68 \%$ & $94 \%(82 \%-100 \%)$ & $95 \%(76 \%-99 \%)$ \\
Benji & Full-Integrity NCR & $33 \%$ & $96 \%(88 \%-100 \%)$ & $92 \%(83 \%-88 \%)$ \\
Benji & Reduced-Integrity NCR & $44 \%$ & $96 \%(90 \%-100 \%)$ & $94 \%(82 \%-100 \%)$ \\
\hline
\end{tabular}




\section{Table 2}

Treatment integrity across participants and phases

\begin{tabular}{|c|c|c|c|c|}
\hline Participant & Phase & $\begin{array}{c}\text { Percentage } \\
\text { of } \\
\text { Sessions } \\
\text { with } \\
\text { Treatment } \\
\text { Integrity }\end{array}$ & $\begin{array}{l}\text { Average Treatment } \\
\text { Integrity: Duration of } \\
\text { Reinforcer Access }\end{array}$ & $\begin{array}{l}\text { Average Treatment } \\
\text { Integrity: Delivery } \\
\text { of Reinforcer }\end{array}$ \\
\hline Charlie & Baseline & $43 \%$ & $62 \%(56 \%-89 \%)$ & $97 \%(90 \%-100 \%)$ \\
\hline Charlie & Full-Integrity NCR & $37 \%$ & $72 \%(36 \%-93 \%)$ & $67 \%(38 \%-93 \%)$ \\
\hline Dante & Baseline & $37 \%$ & $95 \%(71 \%-100 \%)$ & $100 \%(100 \%-100 \%)$ \\
\hline Dante & Full-Integrity NCR & $88 \%$ & $96 \%(77 \%-100 \%)$ & $96 \%(71 \%-100 \%)$ \\
\hline Arik & Baseline & $57 \%$ & $95 \%(80 \%-100 \%)$ & $88 \%(67 \%-100 \%)$ \\
\hline Arik & Full-Integrity NCR & $44 \%$ & $97 \%(86 \%-100 \%)$ & $95 \%(78 \%-100 \%)$ \\
\hline Jack & Baseline & $86 \%$ & $96 \%(67 \%-96 \%)$ & $89 \%(33 \%-100 \%)$ \\
\hline Jack & Full-Integrity NCR & $92 \%$ & $100 \%$ & $99 \%(86 \%-100 \%)$ \\
\hline Jack & Reduced-Integrity NCR & $100 \%$ & $100 \%$ & $98 \%(86 \%-100 \%)$ \\
\hline Herbert & Baseline & $100 \%$ & $73 \%(0 \%-100 \%)$ & $93 \%(50 \%-100 \%)$ \\
\hline Herbert & Full-Integrity NCR & $100 \%$ & $86 \%(33 \%-100 \%)$ & $99 \%(75 \%-100 \%)$ \\
\hline Herbert & Reduced-Integrity NCR & $100 \%$ & $79 \%(20 \%-100 \%)$ & $95 \%(60 \%-100 \%)$ \\
\hline Benji & Baseline & $49 \%$ & $96 \%(75 \%-100 \%)$ & $98 \%(80 \%-100 \%)$ \\
\hline Benji & Full-Integrity NCR & $36 \%$ & $94 \%(29 \%-100 \%)$ & $94 \%(63 \%-100 \%)$ \\
\hline Benji & Reduced-Integrity NCR & $38 \%$ & $99 \%(83 \%-100 \%)$ & $95 \%(72 \%-100 \%)$ \\
\hline
\end{tabular}




\section{Table 3}

Average problem behavior per min during interreinforcer intervals and proportion of reinforcers that followed a response across participants and phases

\begin{tabular}{|c|c|c|c|}
\hline Participant & Phase & $\begin{array}{l}\text { Average Problem } \\
\text { Behavior per Min }\end{array}$ & $\begin{array}{l}\text { Proportion of } \\
\text { Reinforcers that } \\
\text { Followed a } \\
\text { Response }\end{array}$ \\
\hline Charlie & Baseline & 2.99 & .86 \\
\hline Charlie & Full-Integrity NCR & 9.75 & .27 \\
\hline Charlie & NCR DRO & 5.53 & .13 \\
\hline Charlie & NCR Enriched & 4.92 & .18 \\
\hline Dante & Baseline & 1.69 & .97 \\
\hline Dante & Full-Integrity NCR & 1.47 & .09 \\
\hline Arik & Baseline & 22.90 & .90 \\
\hline Arik & Full-Integrity NCR & 15.17 & .46 \\
\hline Jack & Baseline & 25.09 & .97 \\
\hline Jack & Full-Integrity NCR & .43 & .01 \\
\hline Jack & NCR $20 \%$ & .62 & .05 \\
\hline Herbert & Baseline & 5.18 & .94 \\
\hline Herbert & Full-Integrity NCR & .68 & .04 \\
\hline Herbert & NCR $20 \%$ & 5.45 & .41 \\
\hline Herbert & NCR $80 \%$ & 1.57 & .10 \\
\hline Benji & Baseline & 2.47 & .96 \\
\hline Benji & Full-Integrity NCR & .71 & .01 \\
\hline Benji & NCR $20 \%$ & .66 & .11 \\
\hline Benji & NCR $80 \%$ & .94 & .06 \\
\hline
\end{tabular}




\section{Figure 1}

Functional Anaysis Results for All Participants
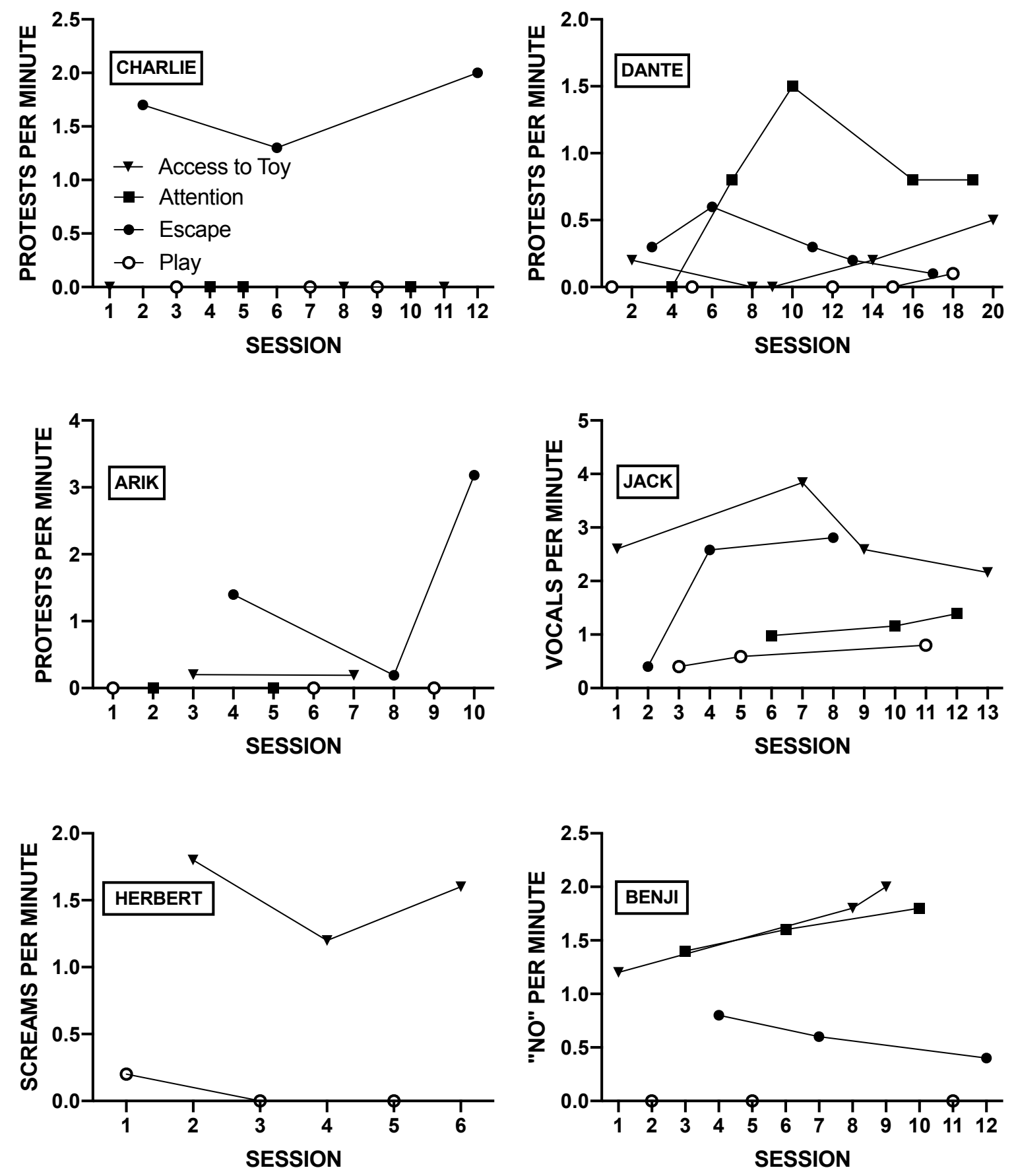

Note. The legend shown in Charlie's graph applies to all graphs. 


\section{Figure 2}

Experiment Results for Charlie, Dante, and Arik
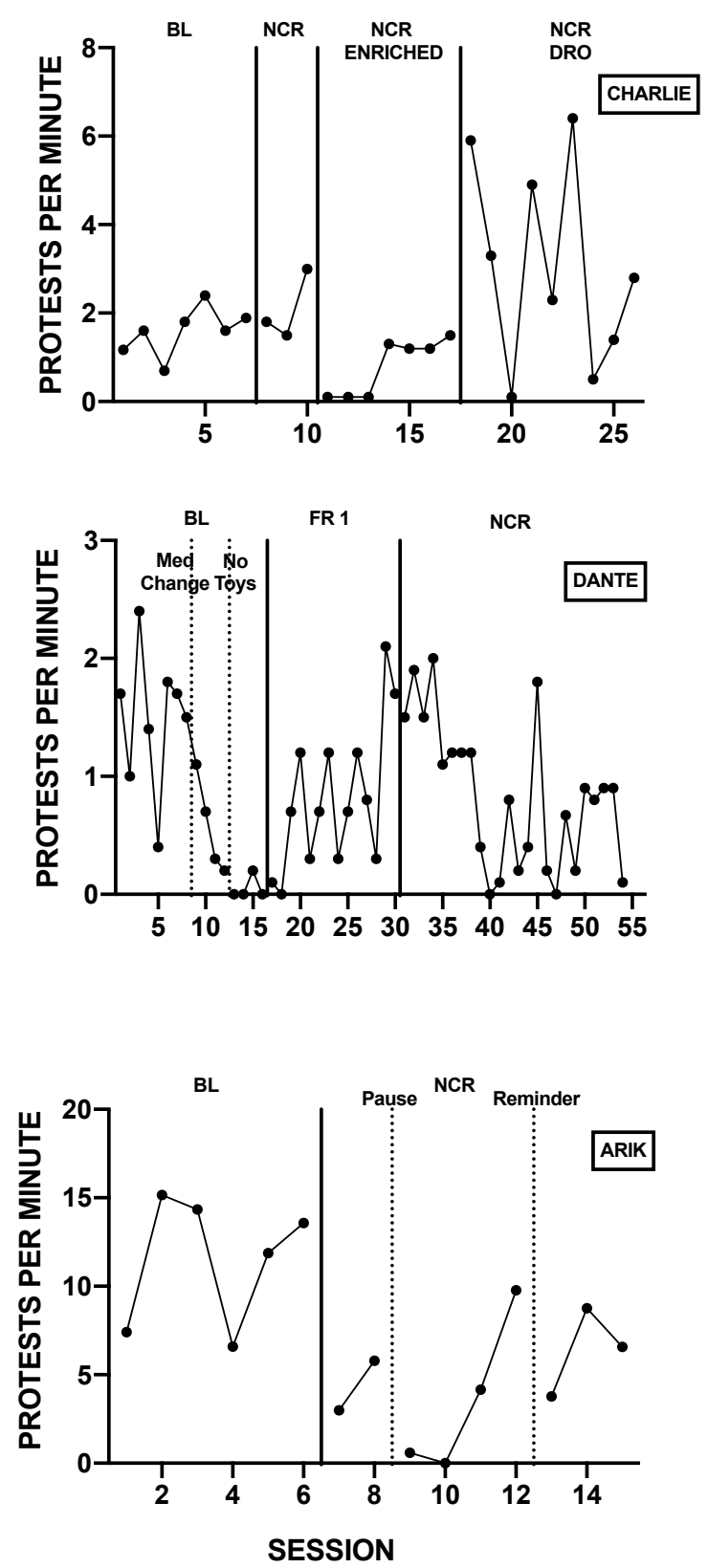

Note. Phase labels of "NCR" refer to full-integrity NCR phases. Dotted phase change lines show within phase changes (medication change and removal of toys for Dante; telling Arik to pause the game and reminding him to pause the game). Note the different y-axis scaling. 


\section{Figure 3}

Experiment Results for Jack, Herbert, and Benji
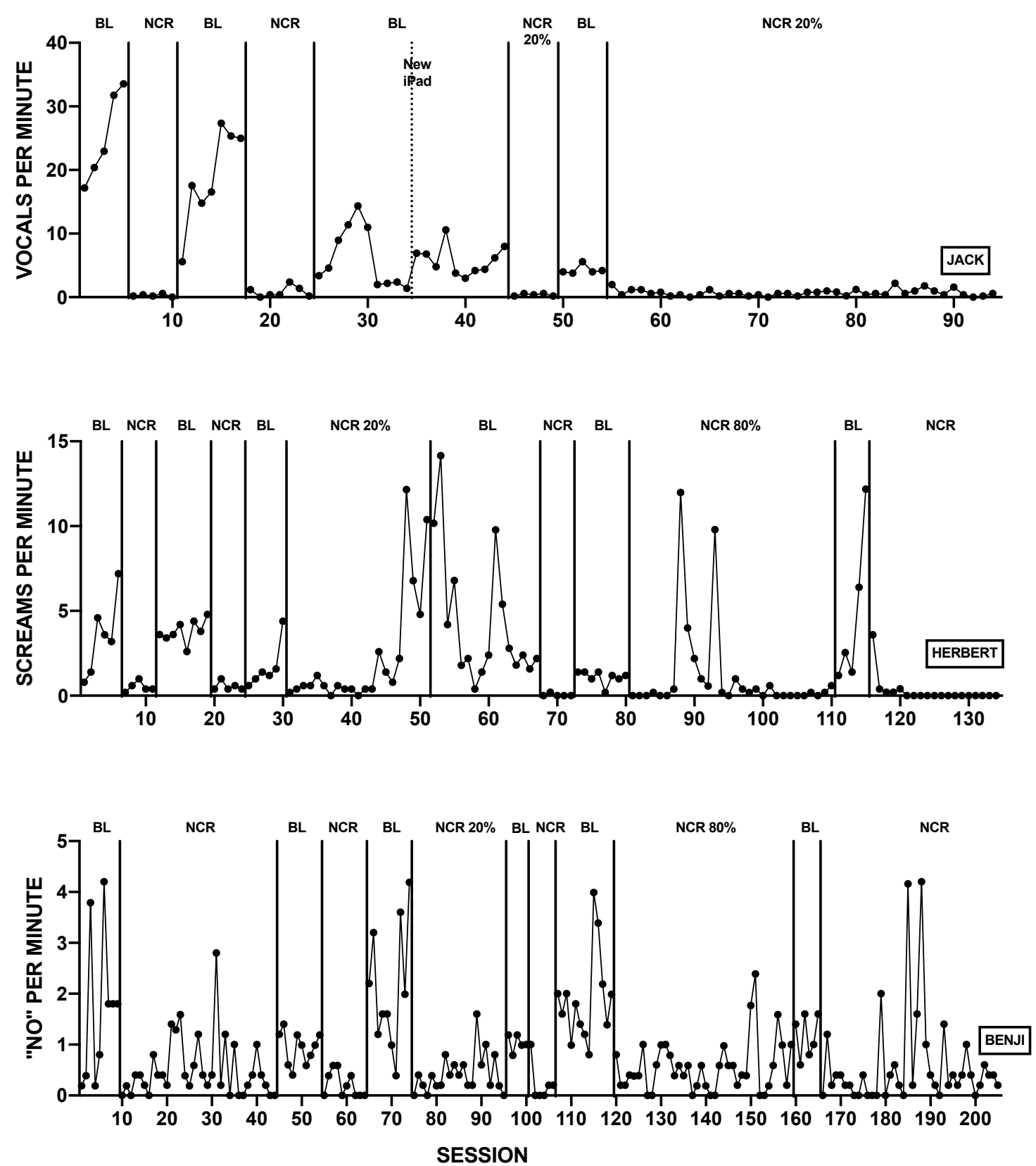

Note. Phase labels of "NCR" refer to full-integrity NCR phases. Reduced integrity treatment phase labels indicate programmed treatment integrity. The dotted line on Jack's graph indicates when we provided a new iPad during reinforcer access periods. Note the different y-axis scaling. 


\section{Figure 4}

Proportion of Reinforcers that Followed a Response by Condition and Participant

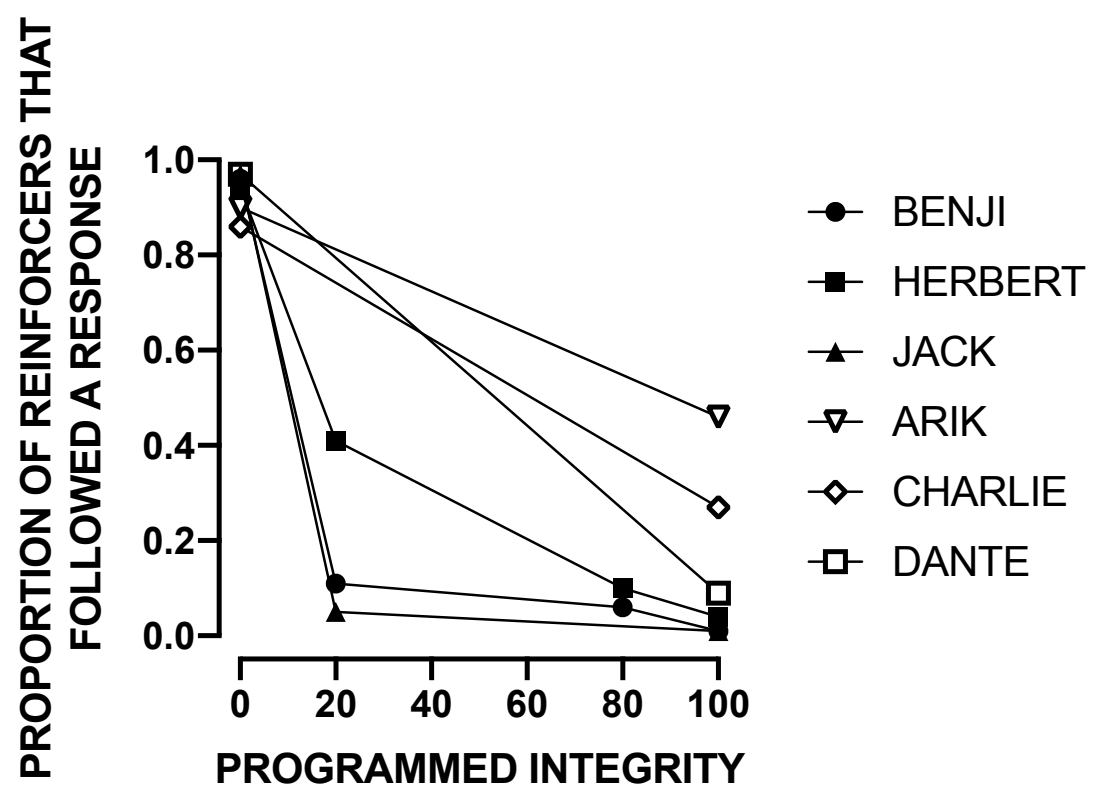

Note. Filled symbols depict all conditions for participants that experienced reduced-integrity conditions. 


\section{Figure 5}

Problem Behavior per Minute and Proportion of Reinforcers that Followed a Response by

\section{Condition}

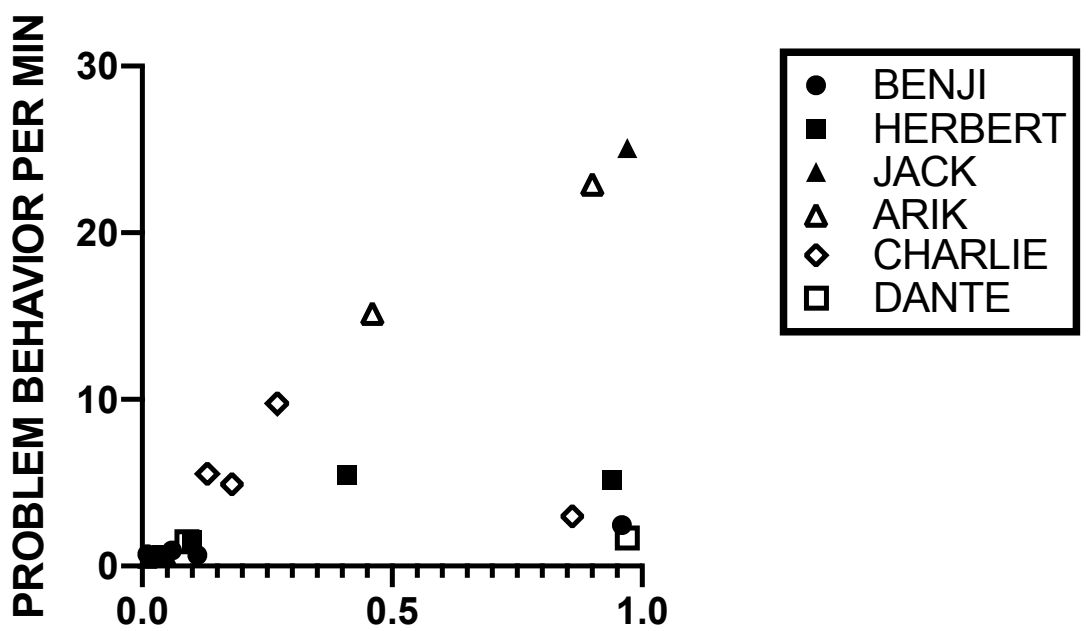

\section{PROPORTION OF REINFORCERS THAT FOLLOWED A RESPONSE}

Note. Filled symbols depict all conditions for participants that experienced reduced-integrity conditions. Problem behavior per min was calculated by dividing the number of responses that occurred during the interreinforcer intervals by the time spent in interreinforcer intervals. 